\title{
Male Circumcision and Risky Sexual Behavior in Zimbabwe: Evidence from the 2010-11 Zimbabwe Demographic and Health Survey
}

\author{
Antony Chikutsa ${ }^{1 *}$; Alfred C. Ncube ${ }^{1}$; and Shephard Mutsau ${ }^{1}$ \\ ${ }^{1}$ Faculty of Applied Social Sciences, Zimbabwe Open University
}

\begin{abstract}
In 2009, Z imbabwe adopted voluntary medical male circumcision (VMMC) as an additional method of HIV prevention. The promotion of VM MC has raised a major concern that it might lead to an increase in high-risk sexual behavior, a phenomenon known as risk compensation or behavioral disinhibition. This study sought to test whether circumcised men in Z imbabwe are more likely to have engaged in risky sexual behavior. The study used data collected from 7,480 men age 15-54 who were interviewed during the 2010-11 Zimbabwe Demographic and Health Survey (ZDHS). Logistic regression was used to assess the association between circumcision and risky sexual behaviors. The study found no statistically significant association between male circumcision and risky sexual behavior. These results suggest a need to continue monitoring the relationships between ongoing VMCC campaigns and men's risky sexual behavior. Information dissemination on VM M C should emphasize caution in messages promoting medical male circumcision to avoid giving the impression that it provides immunity against HIV.
\end{abstract}

Keywords: HIV prevention; voluntary medical male circumcision; risky sexual behavior

\section{Résumé}

En 2009, le Zimbabwe a adopté la circoncision masculine médicale volontaire (CM MV) comme méthode additionnelle de prévention du VIH-sida. L'interrogation que suscitait la promotion de la CMMV était son incidence possible sur l'augmentation des comportements sexuels à risque connue comme phénomène de compensation du risque ou désinhibant. À partir de données collectées auprès de 7480 hommes âgés de 1554 ans lors de l'Enquête Démographique et de Santé de 2010 du Zimbabwe, l'étude examine si les hommes circoncis sont plus à même d'avoir des comportements sexuels à risque. Les résultats issus de la régression logistique montrent une association statistiquement non significative entre la circoncision et le comportement sexuel à risque. Ils suggèrent toutefois la nécessité de maintenir la vigilance sur l'effet éventuel des campagnes de CMMV sur les comportements sexuels à risque. Les informations qui font la promotion de cette méthode se doivent de souligner qu'elle ne constitue pas une immunisation contre le VIH sida.

Mots clé: prévention du VIH-sida; circoncision masculine médicale volontaire; comportements sexuels à risque

\footnotetext{
*Corresponding author: Email: chikutsaa@zou.ac.zw or antony.chikutsa@gmail.com
} 


\section{Introduction}

Zimbabwe has one of the highest HIV prevalence rates in the world, currently estimated at $\mathbf{1 5 . 2}$ percent among adults age 15-49 (ZIMSTAT and ICF International, 2012). W hile HIV can spread through many channels, it has been suggested that most HIV infections (92 percent) in Zimbabwe occur through heterosexual contact, followed by mother-to-child transmission (Zimbabwe $\mathrm{N}$ ational AIDS Council, 2005). Existing approaches to preventing the spread of HIV have mainly been based on the "ABC" approach to behavior change, which promotes abstinence, faithfulness and correct use of condoms. In devising policy guidelines on the effective prevention of new HIV infections, Zimbabwe came up with a Behavior Change Strategy, which focuses on increasing the age at sexual debut, increasing correct condom use, and reducing the average number of sexual partners. The approach also encouraged individuals and couples to get tested for HIV. However, the ABC approach has had limited success in most sub-Saharan African countries (Kerwin et al, 2011). In 2009, Zimbabwe adopted voluntary medical male circumcision (VMMC) as an additional HIV prevention strategy to the existing $A B C$ behavior change model. The campaign for scaling up VMMC for HIV prevention focuses on men from the age of 13 who are HIV-negative. The procedure is offered free of charge at designated public hospitals and health centers throughout the country.

\section{Literature review}

Medical male circumcision has become a significant dimension of HIV prevention interventions, after the results of three randomized controlled trials (RCTs) in U ganda, South Africa and Kenya demonstrated that circumcision has a protective effect against contracting HIV of up to 60 percent for men having sex with women (Auvert et al., 2005; Bailey et al., 2007; Gray et al., 2007). Pursuant to these findings, the World Health Organization (WHO) and UNAIDS recommended that VMMC be implemented immediately as an additional HIV prevention strategy in countries with high HIV prevalence rates but low male circumcision rates (WHO and UN AIDS, 2007).

Notwithstanding the WHO and UNAIDS recommendation, and the promotion of VMMC as an additional HIV prevention strategy in a number of sub-Saharan African countries, including Zimbabwe, fundamental questions remain about whether promoting VMMC as an HIV prevention intervention will result in decreases in HIV incidence. A major concern is that promoting VMMC may lead circumcised men to develop a false sense of effective protection against HIV and engage in risk compensation or behavioral disinhibition. The Zimbabwe $\mathrm{N}$ ational AID S C ouncil (N AC) highlighted concern over the risk compensation behaviors among circumcised men (Yikoniko, 2012). This phenomenon involves either halting or decreasing previous protective behaviors such as condom use or partner reduction, thus reducing or nullifying the protective effects of male circumcision (Westercamp et al., 2012).

However, studies have not found evidence of this phenomenon. Mattson et al (2008) developed an 18item measure of risky sexual behavior for their RCT in Kisumu, Kenya, and found no significant differences in the risk propensity scores between circumcised and uncircumcised men. Another study in Kenya by Westercamp et al (2012) followed up circumcised men after 24 months and compared their perception of risk and their sexual behavior with that of uncircumcised males. The findings supported the earlier findings by Mattson et al (2008). In a related study in Malawi, Godlonton et al (2011) concluded that after learning that circumcision lowers the risk of HIV infection, circumcised men did not become riskier in their sexual behavior. Despite this evidence, there is still debate on the issue of behavioral disinhibition.

In light of the discourse on male circumcision and risky sexual behavior, the present study instead sought to investigate the relationship between male circumcision status and engaging in risky sexual behavior.

\section{Conceptual framework}

The conceptual framework designed for this study shows the possible individual and household factors associated with male circumcision on one hand, and the link between male circumcision status and indicators of risky sexual behavior on the other (see Figure 1).

It is not clear how or when male circumcision began, but it is known that religion has an influence on circumcision. Among Jews and Muslims, male circumcision is practiced as a symbol of keeping the covenant with $\mathrm{God}^{1}$, although circumcision is not mentioned in the Holy Koran (Aldeeb Abu Sahlieh, 1999). Thus, in the present study we have included religion as determinant of circumcision.

\footnotetext{
${ }^{1}$ See Genesis 17:9-14
} 
Another significant determinant of circumcision is ethnicity. Male circumcision has been practiced for many decades as a rite of passage into adulthood among some groups of the X hosa of South Africa and the Aborigines of Australia (Vincent, 2008; Emery, 2005). However, the present study did not include ethnicity as a determinant of circumcision because most national surveys in Zimbabwe, including the ZDHS, do not collect statistics on ethnicity as a national policy.

0 ther studies have linked male circumcision to demographic and socioeconomic variables, such as level of education. The 2004-05 Tanzania DHS shows higher rates of circumcision among men with higher levels of education compared with men with lower levels of education. Tanzanian males with above primary school education had significantly higher odds of being circumcised than those with incomplete primary school education (Wambura et al., 2009). The 2005-06 ZDHS found a weak relationship between education and circumcision; men with primary school education were the most likely to be circumcised (CSO and Macro International, 2007). In Central Uganda the willingness to undergo MMC was found to have an inverse relationship with education (Asiimwe, 2012).

The influence of age as a determinant of male circumcision cannot be understood outside of the context of ethnicity and the generally accepted culture. In many Western countries, and among Jewish people, circumcision is generally performed at birth or within the first week of life (Gallaher, 2000). Among Muslims, circumcision may be performed in early childhood or adolescence. Studies in the United Kingdom have found that circumcision is mostly done by the upper middle class (Gallaher, 2000). In Zimbabwe, traditional circumcision is done at different ages depending on the ethnic group performing the ritual.

Several major surveys have explored the measurement of risky sexual behaviors. Consecutive studies in the British National Survey of Sexual Attitudes and Lifestyles ( $\mathrm{N}$ atsal) have used proxies of risky sexual behavior such as a person's number of sexual partners and condom use during intercourse (Mercer, 2010). Data for common indicators of risky sexual behaviors used by agencies such as UNAIDS ${ }^{2}$ are collected by MEASURE DHS. As well as number of sexual partners and condom use, these indicators also include having paid sex and higher-risk sex (defined as recent sex with a non-marital or noncohabiting partner). In the conceptual framew ork of this study, shown in Figure 1, male circumcision is hypothesized to be a determinant of these risky sexual behaviors.

\footnotetext{
${ }^{2}$ See also

http://www.unaids.org/en/media/unaids/contentassets/d ocuments/document/2010/8_2-Intro-to-Indicators FMEF.pdf
} 
Figure 1: Conceptual framework of male circumcision and risky sexual behavior

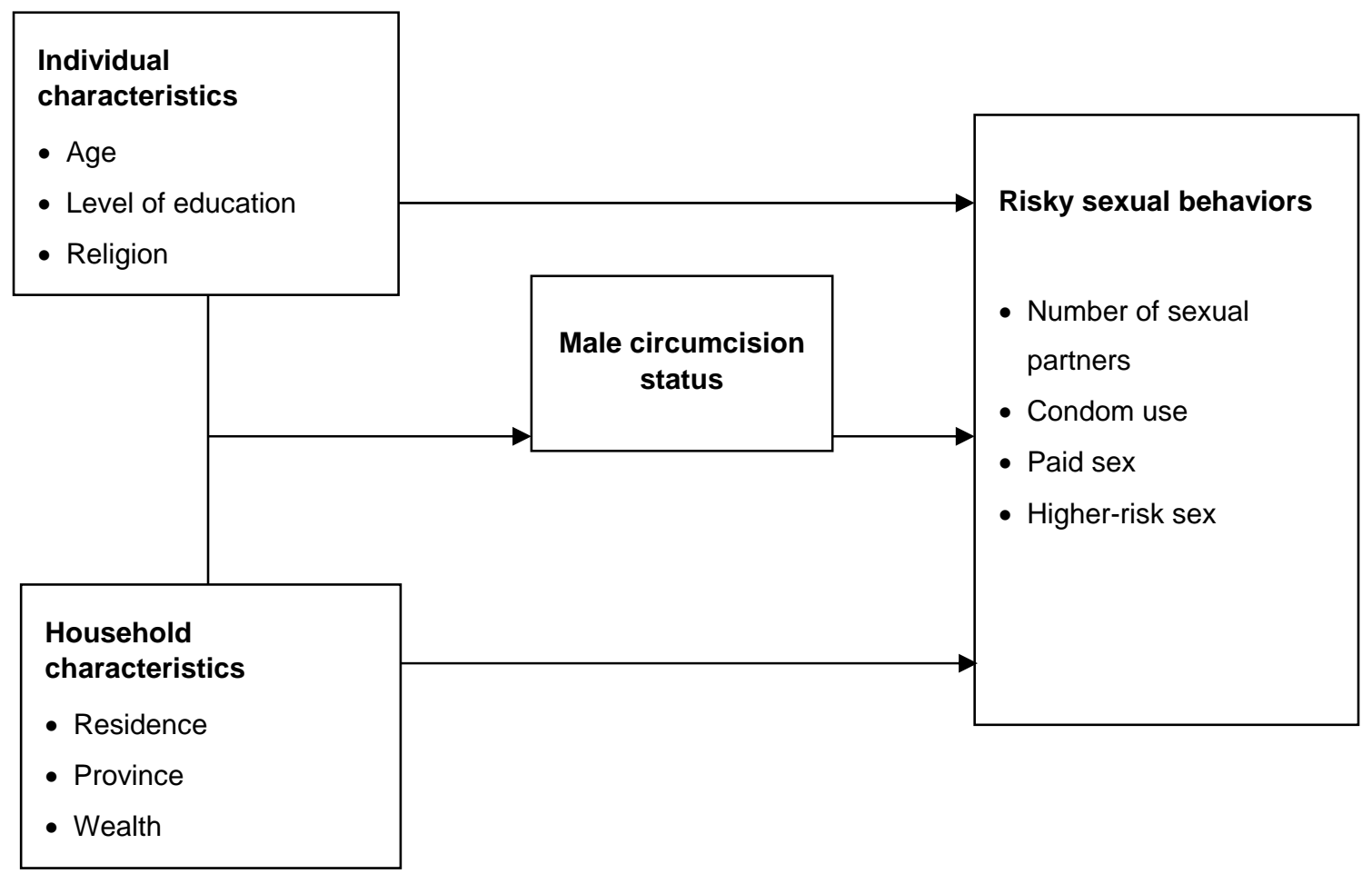

\section{Data and methods}

This study used data on men from the 2010-11 ZDHS. The ZDHS is designed to produce nationally and provincially representative estimates of data on population and health indicators. The survey interviewed men age 15-54 who are usual residents of a household or were visitors who stayed in the household the night before the survey. In total, 7,480 men were interviewed in the survey.

Of particular interest for this study were the data on men's circumcision status and sexual behavior. All interviewed men $(7,480)$ were included in the analysis of factors associated with circumcision, regardless of whether or not the men reported having ever had sex. Individual and household characteristics included in the analysis were men's age, level of education, religion, province, and urban-rural residence. These were considered as determinants of male circumcision. The categories of religion, education and province were collapsed into summary categories according to the characteristics considered to be most salient for the analysis. Proxies of risky sexual behavior were developed and compared between circumcised and uncircumcised men interviewed in the 2010-11 Zimbabwe Demographic and Health Survey (ZDHS). The key variables in the present analysis were defined as highlighted below.

\section{Background Variables}

All of the respondents were grouped into 10-year age groups due to their relative homogeneity. Education was defined as highest level of education attended. Secondary and higher categories were combined into the "Secondary and above" category. Similarly, marital status categories were also combined to produce "never married", "married/living together" and "formerly married" categories. The latter category included all men who reported that they were divorced, separated or widowed at the time of the survey. Wealth was regrouped into terciles at the household level.

For the purposes of this study, Zimbabwe's 10 provinces were collapsed into five groups. Mashonaland Central, Mashonaland East, Mashonaland West and Masvingo provinces were combined into "Mashonaland"; Matabeleland N orth and South and Midlands were combined into "Matabeleland/Midlands"; while Manicaland, Harare and Bulawayo were left as is because of their uniqueness in relation to the rest of the country.

The ZDHS asked respondents to state their religion according to nine categories. For the purposes of this study, respondents were reclassified into four groups: Christian, Muslim, None, and Traditional/O ther.

\section{Circumcision}

There are varying definitions of male circumcision across cultures (Hewett et al., 2012). However, the 
ZDHS defined circumcision as the complete removal of the foreskin. This was necessary to achieve a common understanding of the concept between interviewers and respondents. Thus for this study, circumcision status was determined by the responses to the question: "Some men are circumcised, that is, the foreskin is completely removed from the penis. Are you circumcised?" There were three possible responses to this question: "yes", "no" or "I don't know". A small proportion of men who reported that they did not know their circumcision status were assumed to be uncircumcised.

\section{Risky Sexual Behavior}

Four indicators of risky sexual behavior were considered for this study, as follows:

(1) Paid sex: In the present study, all men who reported to have ever paid for sex were considered to have engaged in risky sexual behavior.

(2) Multiple sexual partners in the past 12 months: Having had two or more sex partners in the 12 months preceding the survey. While this indicator is often reported as a percentage of sexually active men, we considered all men to be 'at risk'; hence the denominator is all men.

(3) Higher-risk sex in the past 12 months: Higher-risk sex is defined as any sexual intercourse with a non-marital or noncohabiting partner, among those who had sex in the 12 months before the survey.

(4) N ot using a condom during last higher-risk sex: Condom use during sexual intercourse is considered a preventive measure against the transmission of sexually transmitted infections (STIS). The ZDHS collected data on condom use in the past 12 months during last sexual intercourse with up to three different partners. Not using a condom at the last sexual intercourse with a high-risk partner was considered a risky behavior. In eight cases, men reported higher-risk sex in the past 12 months, but use of a condom with that partner could not be determined because their last three partners were spousal; these men were excluded from the denominator.

\section{Research Q uestion and Hypothesis}

Risk compensation theory suggests that as the risk of an undesirable outcome is reduced, people may compensate by behaving in riskier ways that keep their overall level of risk constant (cf. Hedlund, 2000). This study was guided by the need to answer a question on the relationship between male circumcision and high-risk sexual behavior. The analysis tests the hypothesis that in Zimbabwe men who are circumcised engage in riskier sexual behaviors. The corresponding null hypotheses for this study are that there is no significant association between male circumcision status and risky sexual behavior, and that there is no significant association between wanting a circumcision and risky sexual behavior.

\section{Data Analysis}

The analysis was done using STATA version 12 . Models were used primarily for two reasons, first to determine the strength of the association between circumcision and background variables, and second, to determine the association between circumcision status and proxies of risky sexual behavior. In the data analysis, we took into account the complex multi-stage sampling design and the weights that were calculated for the ZDHS.

\section{Results}

\section{Sample Characteristics}

Table 1 summarizes the characteristics of the 7,480 men age 15-54 interviewed by the 2010-11 ZDHS. Forty-two percent were age 15-24, while 30 percent were age 25-34. Seventy-six percent of the respondents had at least some secondary education, 51 percent were married or living together, 74 percent gave their religion as Christian, and 63 percent resided in a rural area at the time of the survey. 
Table 1: Sample characteristics

\begin{tabular}{|c|c|c|}
\hline Background characteristic & Weighted percent & Number of men \\
\hline \multicolumn{3}{|l|}{ Age } \\
\hline $15-24$ & 41.6 & 3,107 \\
\hline $25-34$ & 29.5 & 2,207 \\
\hline $35-44$ & 18.9 & 1,417 \\
\hline $45-54$ & 10.0 & 749 \\
\hline \multicolumn{3}{|l|}{ Education } \\
\hline No education & 1.0 & 77 \\
\hline Primary & 23.0 & 1,724 \\
\hline Secondary and above & 75.9 & 5,680 \\
\hline \multicolumn{3}{|l|}{ Religion } \\
\hline Traditional/other & 4.3 & 324 \\
\hline Christians & 73.5 & 5,501 \\
\hline Muslim & 0.6 & 44 \\
\hline None & 21.6 & 1,612 \\
\hline \multicolumn{3}{|l|}{ Marital status } \\
\hline N ever married & 44.5 & 3,329 \\
\hline Married/living together & 50.7 & 3,794 \\
\hline Formerly married & 4.8 & 357 \\
\hline \multicolumn{3}{|l|}{ Residence } \\
\hline Urban & 36.9 & 2,757 \\
\hline Rural & 63.1 & 4,723 \\
\hline \multicolumn{3}{|l|}{ Region } \\
\hline Manicaland & 13.6 & 1,013 \\
\hline Mashonaland & 40.3 & 3,017 \\
\hline Matabeleland/Midlands & 22.3 & 1,669 \\
\hline Harare & 18.3 & 1,371 \\
\hline Bulawayo & 5.5 & 410 \\
\hline Total age $15-54$ & 100.0 & 7,480 \\
\hline
\end{tabular}

Source: ZDHS 2010-11

Table 2 shows the proportion of men reporting risky sexual behavior. Eighteen percent reported having ever paid for sex in their lifetime. Eleven percent of all men reported having had two or more partners in the past 12 months, while 33 percent of sexuallyactive men had sex with a higher-risk partner, that is, a non-marital non-spousal partner, in the past year. Of the men who reported having had a higherrisk partner in the past year, 22 percent did not use a condom during their last sexual encounter with that partner.

Table 2: Indicators of risky sexual behavior

\begin{tabular}{lll}
\hline Indicator & Weighted percent & Denominator \\
\hline Ever paid for sex & 18.0 & 7,480 \\
Two or more partners in the past 12 months & 10.5 & 7,480 \\
Higher-risk sex in the past 12 months & 33.2 & 5,100 \\
Did not use condom use at last higher-risk sex & 22.3 & 1,686 \\
\hline
\end{tabular}

\footnotetext{
${ }^{a}$ Higher-risk sex is defined as sex with a non-marital, non-cohabiting partner in the past 12 months among men who had sex in the past 12 months.

${ }^{\mathrm{b}}$ In eight weighted cases, men who had higher-risk sex in the past 12 months were excluded because their last 3 partners were spouses; condom use with non-spousal partner could not be determined
} 


\section{Characteristics of Circumcised and} Uncircumcised Men

Of the 7,480 men interviewed, 9 percent (685) reported being circumcised. An additional 37 percent of men responded that they would want to be circumcised if it were available for free and were safe. Table 3 shows the proportion of men who are circumcised, want circumcision, or do not want circumcision by their background characteristics. Men age 35-44, men who attended only primary education, Muslim men, men who are married, and men from the Manicaland region are most likely to be circumcised. The proportion of circumcised men is lowest in the Mashonaland region, where only 7 percent of men are circumcised.

Table 3: Characteristics of circumcised and uncircumcised men

\begin{tabular}{|c|c|c|c|c|c|}
\hline \multirow[b]{3}{*}{$\begin{array}{l}\text { Background } \\
\text { characteristics }\end{array}$} & \multicolumn{3}{|c|}{ Circumcision status } & \multirow[b]{3}{*}{ Total } & \multirow[b]{3}{*}{$\begin{array}{l}\text { Number of } \\
\text { men }\end{array}$} \\
\hline & \multirow[b]{2}{*}{ Circumcised } & \multicolumn{2}{|c|}{ Not circumcised } & & \\
\hline & & $\begin{array}{l}\text { Want } \\
\text { circumcision }\end{array}$ & $\begin{array}{l}\text { Do not want } \\
\text { circumcision }^{\text {a }}\end{array}$ & & \\
\hline \multicolumn{6}{|l|}{ Age } \\
\hline $15-24$ & 6.5 & 34.6 & 58.9 & 100.0 & 3,107 \\
\hline $25-34$ & 9.8 & 41.5 & 48.1 & 100.0 & 2,207 \\
\hline $35-44$ & 11.8 & 38.5 & 50.1 & 100.0 & 1,417 \\
\hline $45-54$ & 11.5 & 27.0 & 60.8 & 100.0 & 749 \\
\hline \multicolumn{6}{|l|}{ Education } \\
\hline No education & 9.0 & 21.4 & 69.6 & 100.0 & 77 \\
\hline Primary & 9.8 & 28.9 & 61.3 & 100.0 & 1,724 \\
\hline Secondary and above & 9.0 & 39.2 & 51.8 & 100.0 & 5,680 \\
\hline \multicolumn{6}{|l|}{ Religion } \\
\hline Traditional/other & 12.6 & 40.5 & 46.9 & 100.0 & 324 \\
\hline Christians & 8.7 & 37.3 & 54.0 & 100.0 & 5,501 \\
\hline Muslim & 77.9 & 14.7 & 7.4 & 100.0 & 44 \\
\hline None & 8.0 & 34.1 & 57.9 & 100.0 & 1,612 \\
\hline \multicolumn{6}{|l|}{ Marital status } \\
\hline N ever married & 6.6 & 34.7 & 58.7 & 100.0 & 3,329 \\
\hline Married/living together & 11.2 & 37.8 & 51.0 & 100.0 & 3,794 \\
\hline Formerly married & 10.7 & 41.0 & 48.3 & 100.0 & 357 \\
\hline \multicolumn{6}{|l|}{ Residence } \\
\hline Urban & 9.7 & 40.4 & 49.9 & 100.0 & 2,757 \\
\hline Rural & 8.8 & 34.5 & 56.7 & 100.0 & 4,723 \\
\hline \multicolumn{6}{|l|}{ Region } \\
\hline Manicaland & 13.1 & 32.3 & 54.5 & 100.0 & 1,013 \\
\hline Mashonaland & 6.9 & 34.8 & 58.4 & 100.0 & 3,017 \\
\hline Matabeleland/Midlands & 11 & 38.3 & 50.7 & 100.0 & 1,669 \\
\hline Harare & 8.6 & 38.6 & 52.9 & 100.0 & 1,371 \\
\hline Bulawayo & 12.4 & 47.1 & 40.5 & 100.0 & 410 \\
\hline Total age 15-54 & 9.2 & 36.6 & 54.2 & 100.0 & 7,480 \\
\hline
\end{tabular}

${ }^{a}$ Includes men who either didn't know if they were circumcised or didn't know if they would want to be (54 and 146 weighted cases, respectively) 
The 2010-11 ZDHS did not ask circumcised men whether they were circumcised as a result of Zimbabwe's voluntary medical male circumcision (VMMC) campaign, but did ask about their age at circumcision and who performed their circumcision. $N$ early half of men (47 percent) were circumcised before age 5 , while 31 percent of respondents were circumcised at age 15 or above. As mentioned, Zimbabwe's male circumcision campaign was scaled up in 2009; few of the respondents in the 2010-11 ZDHS had been circumcised in the two years preceding the survey. ${ }^{3}$ Moreover, only health professionals are employed as part of the VMMC program, whereas 58 percent of the circumcised men were circumcised by a traditional practitioner or a family friend, while 24 percent were circumcised by a health professional. In all, the findings indicate that relatively few men interviewed by the ZDHS could have been circumcised as a result of the VMMC campaign.

\section{Factors Associated with Male Circumcision}

The present study analyzed background factors that are associated with male circumcision. We fitted logistic regression models and computed unadjusted and adjusted odds ratios. Table 4 presents the results of the analysis. Unadjusted odds ratios of being circumcised increase with men's age, which is consistent with later ages of circumcision overall in Zimbabwe. Ever-married men are significantly more likely to be circumcised. Education and urban-rural residence are not significantly associated with circumcision.

After controlling for other factors, age is not significantly associated with circumcision; only religion, province, and marital status are significant in the adjusted odds ratios (see Table 4). Married men are more likely to be circumcised compared with never-married men. Men in Mashonaland and $\mathrm{H}$ arare are significantly less likely to be circumcised compared with men in Manicaland (the reference group). Muslim men are overwhelmingly more likely to be circumcised compared with other religions.

\footnotetext{
${ }^{3}$ The circumcision scale-up began in 2009 and the survey was fielded in 2010-2011. In the ZDHS 58 men (weighted $=62.6$ cases) reported having been circumcised in the past two years.
} 
Table 4: Factors associated with male circumcision

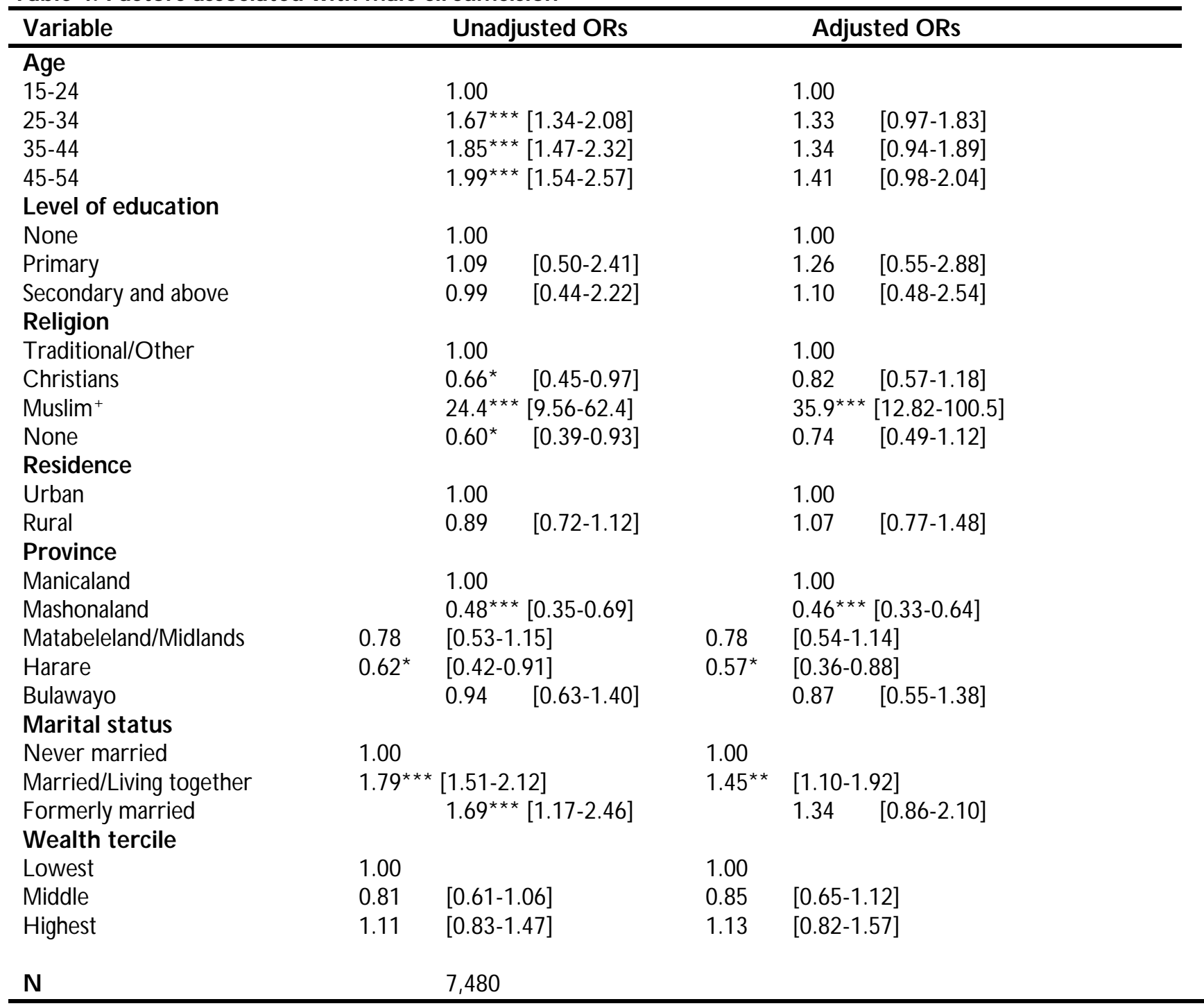

Exponential coefficients; 95percent confidence intervals in brackets

$* p<0.05, * * p<0.01, * * * p<0.001$

+ based on $<50$ weighted cases

"Mashonaland Province" includes Mashonaland East, Mashonaland West, Mashonaland Central and Masvingo

"Matabeleland/Midlands" includes Matabeleland N orth, Matabeleland South

and Midlands

\section{Male Circumcision and Risky Sexual Behavior}

The major objective of this study was to determine if there are significant differences among circumcised and uncircumcised men in engaging in risky sexual behavior. We examined unadjusted and adjusted odds of the association between male circumcision and risky sexual behaviors, as shown in Tables 5-8. The unadjusted odds ratios show that circumcised men are significantly more likely to have ever paid for sex (Table 5) and to have had multiple sexual partners in the past 12 months (Table 6). However, these associations are not statistically significant after adjusting for other background factors. Being circumcised is not significantly associated with higher-risk sex in the past 12 months (Table 7) nor with condom use at last higher-risk sex (Table 8).

The adjusted models for each of these dependent variables indicate that older men and men who have ever been married are more likely to have ever paid for sex (Table 5). Ever-married men also have more than twice the relative odds of having multiple sexual partners in the past 12 months, while men's age has an inverse association with having multiple sexual partners (Table 6). Currently and formerly married men are significantly less likely to have had higherrisk sex in the past 12 months. W ealth and education have no significant relationship with higher-risk sexual behaviors. The relationship between province 
African Population Studies Vol 28 no 2 Supplement July 2014

and risky sexual behavior is inconsistent across indicators.

Table 5: Unadjusted and adjusted odds ratios of having ever paid for sex, by circumcision status

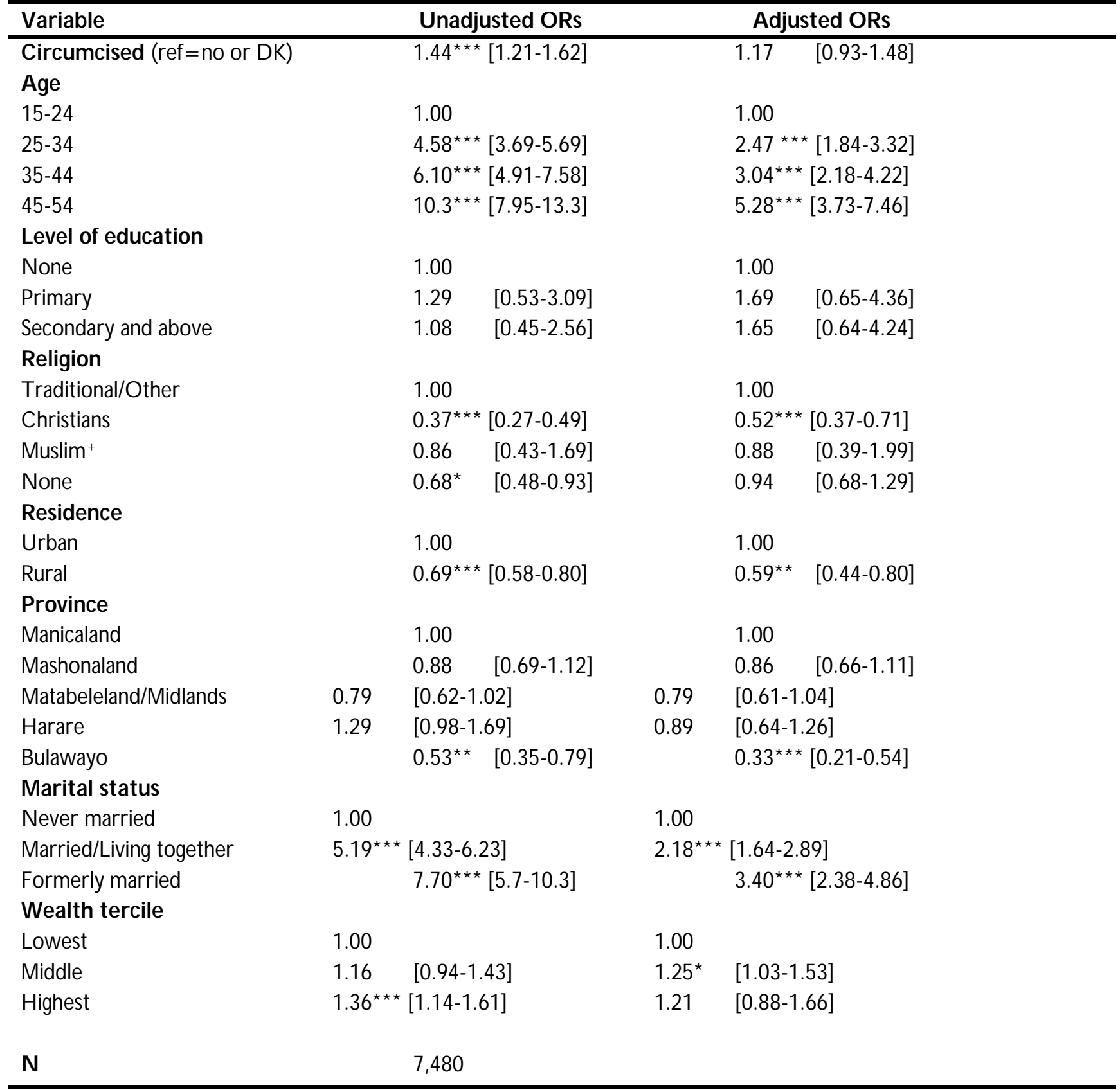

Exponential coefficients; 95 percent confidence intervals in brackets

$* p<0.05, * * p<0.01, * * * p<0.001$

+ based on $<50$ weighted cases

"Mashonaland Province" includes Mashonaland East, Mashonaland West, Mashonaland C entral and Masvingo

"Matabeleland/Midlands" includes Matabeleland N orth, Matabeleland South and Midlands 
Table 6: Unadjusted and adjusted odds ratios of having multiple sex partners in the past 12 months, by circumcision status

\begin{tabular}{|c|c|c|c|c|c|c|}
\hline \multirow{2}{*}{$\begin{array}{l}\text { Variable } \\
\text { Circumcised (ref=no or DK) }\end{array}$} & & \multicolumn{2}{|c|}{ Unadjusted ORs } & \multicolumn{3}{|c|}{ Adjusted ORs } \\
\hline & & $1.33^{*}$ & {$[1.03-1.72]$} & & 1.21 & [0.92-1.59] \\
\hline \multicolumn{7}{|l|}{ Age } \\
\hline $15-24$ & \multicolumn{3}{|c|}{1.00} & \multicolumn{2}{|r|}{1.00} & \\
\hline $25-34$ & \multicolumn{3}{|c|}{$2.03^{* * *}[1.67-2.46]$} & \multicolumn{2}{|r|}{0.95} & {$[0.92-1.59]$} \\
\hline $35-44$ & & $1.52 * *$ & {$[1.19-1.94]$} & \multicolumn{2}{|r|}{0.63} & [0.68-1.33] \\
\hline $45-54$ & & 1.27 & {$[0.91-1.76]$} & \multicolumn{2}{|r|}{$0.55^{* *}$} & {$[0.43-0.89]$} \\
\hline \multicolumn{7}{|l|}{ Level of education } \\
\hline None & \multicolumn{3}{|c|}{1.00} & \multirow{2}{*}{\multicolumn{2}{|c|}{$\begin{array}{l}1.00 \\
0.97\end{array}$}} & \\
\hline Primary & & 0.95 & {$[0.37-2.45]$} & & & {$[0.37-2.52]$} \\
\hline Secondary and above & & 1.10 & {$[0.43-2.85]$} & \multicolumn{2}{|r|}{1.22} & {$[0.48-3.10]$} \\
\hline \multicolumn{7}{|l|}{ Religion } \\
\hline Traditional/O ther & \multicolumn{3}{|c|}{1.00} & \multicolumn{3}{|c|}{1.00} \\
\hline Christians & & $0.61^{*}$ & {$[0.41-0.91]$} & & 0.69 & {$[0.46-1.02]$} \\
\hline Muslim+ & & 0.94 & {$[0.27-3.28]$} & & 0.86 & {$[0.24-3.12]$} \\
\hline None & & 0.97 & {$[0.65-1.42]$} & & 1.06 & {$[0.73-1.55]$} \\
\hline \multicolumn{7}{|l|}{ Residence } \\
\hline Urban & \multicolumn{3}{|c|}{1.00} & \multicolumn{3}{|c|}{1.00} \\
\hline Rural & \multicolumn{3}{|c|}{0.84} & \multicolumn{2}{|r|}{0.69} & {$[0.48-1.01]$} \\
\hline \multicolumn{7}{|l|}{ Province } \\
\hline Manicaland & \multicolumn{3}{|c|}{1.00} & \multicolumn{3}{|c|}{1.00} \\
\hline Mashonaland & & \multicolumn{2}{|c|}{$0.76 \quad[0.56-1.05]$} & & \multicolumn{2}{|c|}{$0.72 * \quad[0.53-0.98]$} \\
\hline Matabeleland/Midlands & 0.81 & \multicolumn{2}{|c|}{$[0.58-1.13]$} & 0.81 & \multicolumn{2}{|c|}{$[0.58-1.13]$} \\
\hline Harare & 0.97 & {$[0.66-1$} & 42] & 0.82 & {$[0.52-1$} & 29] \\
\hline Bulaw ayo & & $0.66 *$ & {$[0.44-0.99]$} & & $0.61^{*}$ & {$[0.38-0.98]$} \\
\hline Marital status & & & & & & \\
\hline $\mathrm{N}$ ever married & 1.00 & & & 1.00 & & \\
\hline M arried/Living together & $2.36 * * *$ & {$[1.93-2$.} & & $2.84 * *$ & {$[2.01-4$} & \\
\hline Formerly married & & $2.42^{* * *}$ & {$[1.59-3.66]$} & & $2.87^{* * *}$ & [1.68-4.91] \\
\hline Wealth tercile & & & & & & \\
\hline Lowest & 1.00 & & & 1.00 & & \\
\hline Middle & 0.92 & {$[0.71-1$} & .19] & 0.89 & {$[0.71-1$} & \\
\hline Highest & 0.95 & {$[0.76-1$} & 72] & 0.77 & {$[0.53-1$} & 11] \\
\hline $\mathbf{N}$ & & 7,480 & & & & \\
\hline
\end{tabular}

Exponential coefficients; 95 percent confidence intervals in brackets

$* p<0.05, * * p<0.01, * * * p<0.001$

+ based on $<50$ weighted cases

"Mashonaland Province" includes Mashonaland East, Mashonaland West, Mashonaland C entral and Masvingo

"Matabeleland/Midlands" includes Matabeleland N orth, Matabeleland South and Midlands 
Table 7: Unadjusted and adjusted odds ratios of higher-risk sex in the past 12 months, by circumcision status

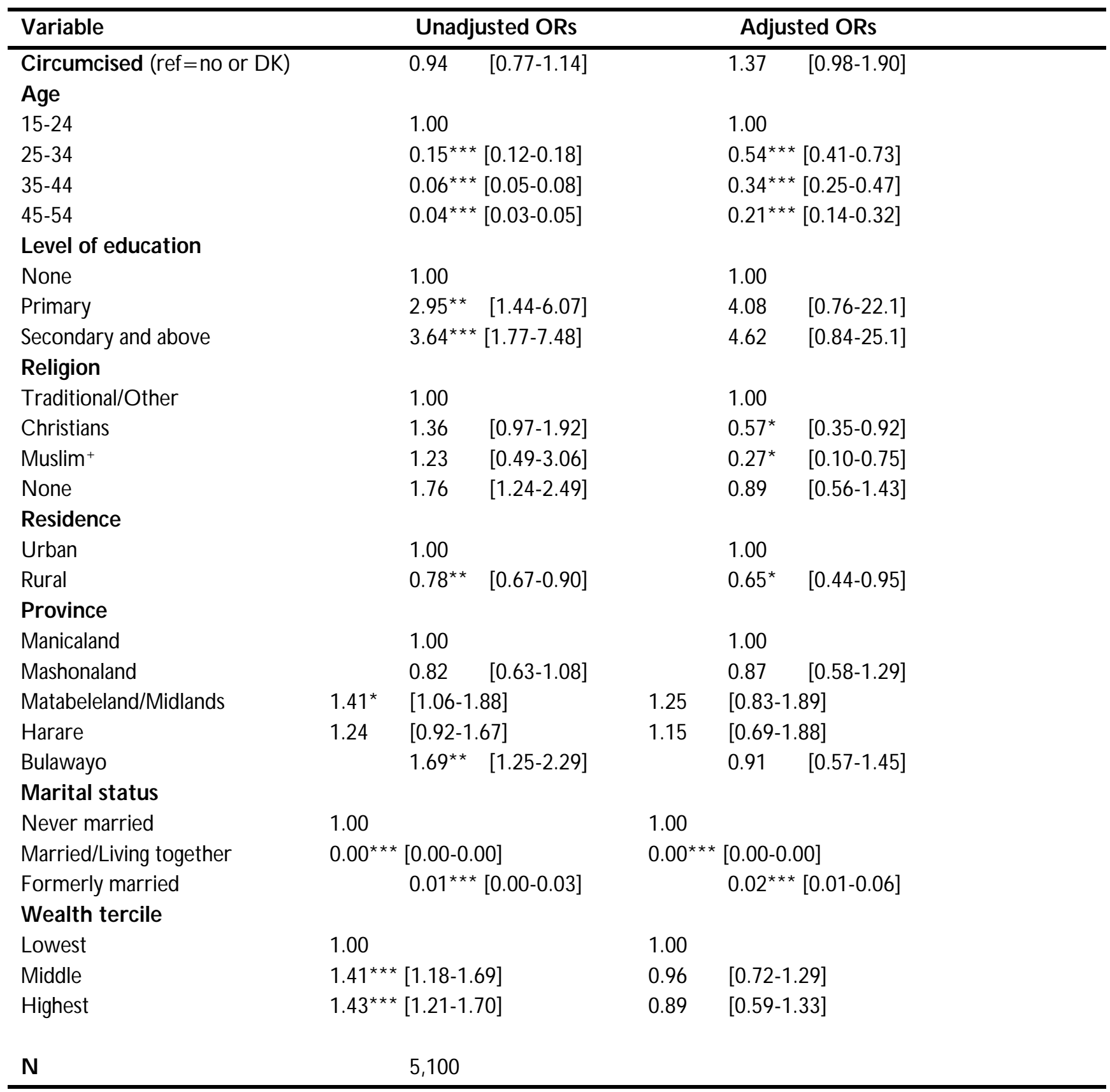

Higher-risk sex is defined as sex with a non-marital, non-cohabiting partner in the past 12 months.

Exponential coefficients; 95 percent confidence intervals in brackets

$* p<0.05, * * p<0.01, * * * p<0.001$

+ based on $<50$ weighted cases

"Mashonaland Province" includes Mashonaland East, Mashonaland West, Mashonaland Central and Masvingo

"Matabeleland/Midlands" includes Matabeleland N orth, Matabeleland South and Midlands 
Table 8: Unadjusted and adjusted odds ratios of not using a condom at last higher-risk sex, by circumcision status

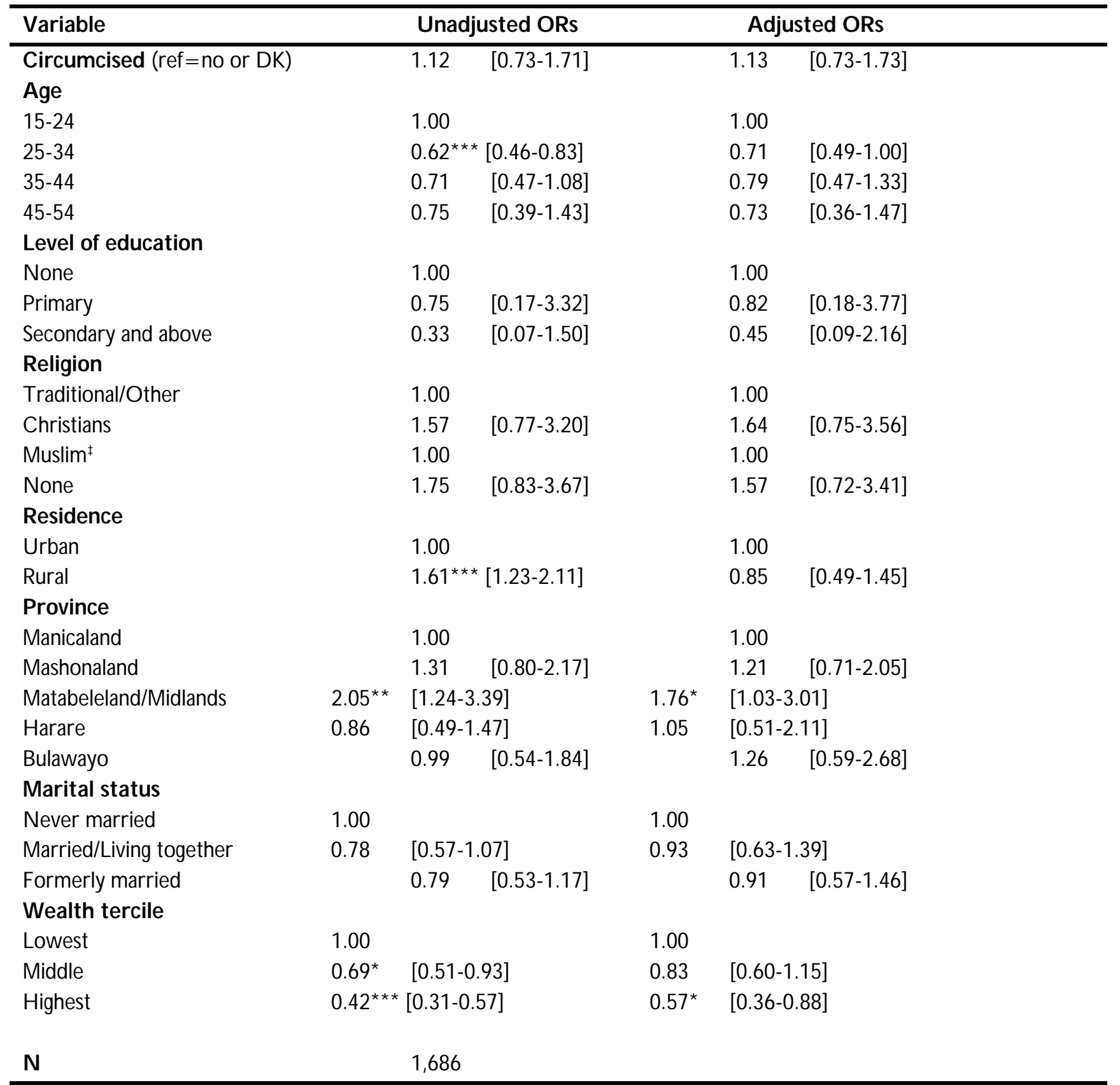

\footnotetext{
$\mathrm{N}$ ot using a condom at last sexual encounter with a non-marital, non-cohabiting partner in the past 12 months, among men who had such a partner. Eight cases were excluded because men's last three partners were spousal, so they were not eligible for questions about condom use with the last high-risk partner.

Exponential coefficients; 95 percent confidence intervals in brackets

$* p<0.05, * * p<0.01, * * * p<0.001$

₹ eliminated due to perfect collinearity; all 12 Muslim men who had higher-risk sex in past year used a condom during their last encounter.

"Mashonaland Province" includes Mashonaland East, Mashonaland West, Mashonaland C entral and Masvingo

"Matabeleland/Midlands" includes Matabeleland N orth, Matabeleland South and Midlands
}

\section{Discussion and conclusion}

The present study investigated the association between male circumcision and risky sexual behavior among men who participated in the 201011 ZDHS. The study is set against the backdrop of the recent promotion in Zimbabwe of voluntary medical male circumcision as an additional HIV prevention method. VMMC has raised fears among critics of the program on the basis that circumcision would lead to an increase in high-risk behavior. These fears emanate from the concern that circumcised men might experience a decline in the perception of their risk of contracting HIV, a 
phenomenon known as risk compensation or behavioral disinhibition.

The study results support the null hypothesis that there is no association between male circumcision and risky sexual behavior. These results are in line with earlier findings from studies in Kenya (Mattson et al., 2008, Westercamp et al., 2012). While the current study is limited to cross-sectional data and thus cannot establish causality, the lack of a relationship between circumcision and risky sexual behavior likely reflects the fact that men are circumcised for many reasons besides HIV prevention. In fact, given the timing of the ZDHS fieldw ork (2010-11) in relation to the scale-up of the VMMC campaign (2009), few men surveyed are likely to have been circumcised as a result of the campaign.

All in all, the findings of this study do not support the argument that circumcised men are prone to engage in risky sex behaviors compared with uncircumcised men. The lack of observed relationship between medical male circumcision and risky sex may be due to the short period between the start of the male medical circumcision in Zimbabwe which started in 2009 and the collection of ZDHS data (2010-2011). Subsequent surveys in Zimbabwe may indeed find a significant association between circumcision and sexual risk-taking behavior.

The results of this study lead us to make the following recommendations. First, there is a need to continue observing the relationship between ongoing medical male circumcision campaigns and risky sexual behavior. Second, communication and information dissemination policy must emphasize the need to take caution in messages promoting medical male circumcision, to avoid giving the false impression that circumcision provides immunity against HIV. Finally, we recommend that there is a need to continue studies on the acceptability and feasibility of medical male circumcision among noncircumcised populations with high incidence of HIV.

\section{Acknowledgments}

We would like to express our most sincere gratitude to ICF International and USAID for funding us through the MEASURE DHS Fellowship program. We are very grateful to our facilitators Sarah Staveteig (PhD), Wenjuan Wang (PhD), Kerry MacQ uarrie, Ambrose Akinlo (PhD), and Samwel Mbugua. Special mention goes to Sarah for her constructive comments on our paper. We are also greatly indebted to our colleagues in the 2013 DHS Fellowship program for their support and feedback.
We also wish to thank Joanna Lowell (PhD) for her reviews of earlier drafts, and Bryant Robey for editing the initial working paper.

\section{Authors' contribution}

AC conceived the study and led the data analysis and writing process.

ACN substantially contributed to the writing and reviewing of the paper.

SM participated in the analysis and writing.

All authors read and approved the final manuscript.

\section{References}

Aldeeb, Abu, and S.A. Sahlieh. 1999. "Muslims' Genitalia in the hands of the Clergy: Religious Arguments about Male and Female Circumcision." In Male and Female Circumcision, Medical, Legal, and Ethical Considerations in Pediatric Practice, edited by C.G. Denniston, F.M. Hodges, and M.F. Milos. New York, New York, USA: Kluwer Academic/Plenum Publishers.

Asiimwe, E. 2012. "Personal Willingness to Undergo Safe Male Circumcision (SMC) among Young Men in Uganda Decreases with Increased Education." The Journal of Global Health. Accessed online at http://www.ghjournal.org/jghprint/spring-2012-print-issue/personalwillingness-to-undergo-safe-male-circumcisionsmc-among-young-men-in-rural-ugandadecreases-with-increased-educational-attainment

Auvert, B., D. Taljaard, E. Lagarde, J. SobngwiTambekou, R. Sitta, and A. Puren. 2005. "Randomized, Controlled Intervention Trial of Male C ircumcision for Reduction of HIV Infection Risk: The ANRS 1265 Trial." PLoS Med 2 (11): e298.

Bailey, R.C., S. Moses, C.B. Parker, K. Agot, I. Maclean, J.N. Krieger, C.F.M. Williams, R.T. Campbell, and J.O. N dinya-Achola. 2007. "Male Circumcision for HIV Prevention in Young Men in Kisumu, Kenya: A Randomised Controlled Trial." The Lancet 369 (9562): 643-656.

Central Statistical Office (CSO) [Zimbabwe], and Macro International Inc. 2007. Zimbabwe Demographic and Health Survey 2005-06. Calverton, Maryland, USA: CSO and Macro International Inc.

Emery, L. 2005. "Embodying the Wound or Wounding the Body? Circumcision as Transformation and Expiation." Accessed online at www.mytho-logos.net. 
Gallaher, D.L. 2000. Circumcision: A History of the W orld's Most Controversial Surgery. New York, N ew York, USA: Basic Books.

Global Report UN AIDS. 2012. "UN AIDS Report on the Global AIDS Epidemic." Accessed online at http://www.unaids.org/en/media/unaids/contenta ssets/documents/epidemiology/

2012/gr2012/20121120_UN AIDS_Global_Report _2012_with_annexes_en.pdf

Godlonton, S., Munthali, A., and Thornton, R. 2011. "Behavioral Response to Information? Circumcision, Information and HIV Prevention." BREAD working paper No 313. Accessed online at

http://www.povertyactionlab.org/publication/beh avioral-response-information-circumcisioninformation-and-hiv-prevention

Gray, R.H., G. Kigozi, D. Serwadda, F. Makumbi, S. Watya, F. N alugoda, N. Kiwanuka, L.H. Moulton, M.A. Chaudhary, M.Z. Chen, N.K. Sewankambo, F. Wabwire-Mangen, M.C. Bacon, C.F.M. Williams, P. Opendi, S.J. Reynolds, 0. Laeyendecker, T.C. Quinn, and M.J. Wawer. 2007. "Male Circumcision for HIV Prevention in Men in Rakai, U ganda: A Randomised Trial." The Lancet 369(9562): 657-666.

Hedlund, J. 2000. "Risky Business: Safety Regulations, Risk Compensation, and Individual Behavior." Injury prevention 6(2): 82-89.

Hewett, P.C., N. Haberland, L. Apicella, and B.S. Mensch. 2012. "The (Mis)Reporting of Male Circumcision Status among Men and Women in Zambia and Swaziland: A Randomized Evaluation of Interview Methods." PLOS ONE 7(5): e36251.

Kerwin, J. T., Foley, S. M., Thornton, R. L., Basinga, P., Chinkhumba, J. (2011) Missing safer

sex strategies in HIV Prevention: A call for further research. African Population Studies Vol. 25, 2 (Dec 2011)

Mattson, C., R.T. Campbell, R.C. Bailey, K. Ago, J.0 . $\mathrm{N}$ dinya-Achola, and S. Moses. 2008. "Risk Compensation Is $\mathrm{N}$ ot Associated with Male Circumcision in Kisumu Kenya: A Multi-Faceted Assessment of Men Enrolled in a Randomized Controlled Trial." PLos ONE 3(6).
Mercer, C. 2010. "Measuring Sexual Behavior and Risk." Accessed online at http://surveynet.ac.uk/sqb/topics/healthbehaviour Isqb sex mercer.pdf

UN AIDS. 2010. UN AIDS Report on the Global AIDS Epidemic. The Global Reference Book on the AID S Epidemic and Response. Accessed online at http://www .avert.org/aids-

zimbabwe.htm\# references

Vincent, L. 2008. "'Boys Will Be Boys': Traditional Xhosa Male Circumcision, HIV and Sexual Socialisation in Contemporary South Africa." Culture, Health \& Sexuality 10(5): 431-46.

Wambura, M., J. Mwanga, J. Mosha, G. Mshana, F. Mosha, and J. Changalucha. 2009. Situation Analysis for Male Circumcision in Tanzania, Final Report. Dar es Salaam, Tanzania: Ministry of $\mathrm{H}$ ealth and Social Welfare, and $\mathrm{N}$ ational Institute for Medical Research.

Westercamp, M., K. Agot, J.O . N dinya-Achola, and R.C. Bailey. 2012. "Circumcision Preference among Women and Uncircumcised Men Prior to Scale-Up of Male Circumcision for HIV prevention in Kisumu, Kenya." AIDS Care 24(2): 157-66.

WHO, and UNAIDS. 2007. "New Data on Circumcision and HIV Prevention and Programme Implications and Recommendations." Presented at Montreux, March 6-9 2007. Accessed online at http://libdoc.who.int/publications/2007/97892415 95988 eng.pdf

Yikoniko, S. 2012. Circumcised Men not Spared from HIV Infection. In The Sunday Mail of July 814, 2012, Harare, Zimbabwe.

Zimbabwe National AIDS Council (NAC). 2005. Behaviour Change Research. Harare, Zimbabwe: NAC.

Zimbabwe National Statistics Agency (ZIMSTAT), and ICF International. 2012. Zimbabwe Demographic and Health Survey 2010-11. Calverton, Maryland, USA: ZIMSTAT and ICF International Inc. 